\title{
Influence of Plastic Deformation on Magnetic Transition in Soft Magnetic Amorphous Alloys
}

\author{
J. Miškuf, K. Csach And A. Juríková \\ Institute of Experimental Physics, Slovak Academy of Sciences, Watsonova 47, 04001 Košice, Slovakia \\ The influence of the intensive plastic deformation on the structure of ferromagnetic amorphous alloys has \\ been studied by means of thermoanalytical methods. It was shown that the work of plastic deformation led to the \\ local heating in thin shear band layers and the dissipation of the energy caused structural changes in the region \\ outside these bands. The plastic deformation influences the structure of the alloys and their structural sensitive \\ magnetic properties.
}

PACS: 61.43.Dq, 62.20.Hg

\section{Introduction}

In recent years the range of available soft magnetic materials has been significantly increased by the development of amorphous metallic glasses or nanocrystalline alloys produced by rapid solidification of the melt. One of the disadvantages of these materials is their form and low reforming ability [1,2]. The plastic deformation of metallic glasses is carried out via the shear band creation and the shear in these bands. It was shown that the catastrophic shear band creation was done under nearly adiabatic conditions. The stored elastic energy releases during local heating of the material in the thin layer of the shear band. At the final stage of the deformation the manifestations of local heating are observed as dimples or needles at fracture surface of failed metallic glasses [3, 4]. The physical process of the plastic deformation of glassy materials can be facilitated by collective atomic motions, which requires some sufficient energy to overcome the bonding force among the atoms. It results in an increase of the free volume [5]. During the plastic deformation of metallic glasses, the areas of the specimens can be categorized into two kinds of regions according to their highly-localized deformation behavior: the shear band regions that accumulate mainly the plastic deformation and the outside shear band regions that simultaneously undergo elastostatic loading [6].

The influence of plastic deformation on the ductility of amorphous alloys was intensively studied mainly for the alloys with excellent glass forming ability - bulk metallic glasses (BMGs) [5, 7]. It was shown that the multiplication of shear bands is the effective way to ductilize BMGs [6]. During the plastic compression of specimens, the outside shear band regions underwent the elastostatic loading. Subsequently the shear bands initiate in the elastostatically loading regions. The structural relaxation (i.e. the annihilation of excess free volume) in the BMGs is proportional to the enthalpy changes during heating [8].

The study of influence of the plastic deformation on the nanocrystallization of Finemet alloy revealed that although the given plastic deformation does not influence the crystallization [9], the changes in the magnetization of the amorphous state due to the plastic deformation were observed. The aim of this work was to compare the structural changes of as-quenched, relaxed and deformed amorphous states.

\section{Experimental}

Structural changes of as cast amorphous ribbons $\mathrm{Fe}_{73.5} \mathrm{Nb}_{3} \mathrm{Cu}_{1} \mathrm{Si}_{13.5} \mathrm{~B}_{9}$ were introduced by the repeated impacting of small hammer during $10 \mathrm{~min}$. The differential thermal analysis (DTA) and the study of the magnetization were carried out by means of thermal analysis equipment Setaram TGDTA92 adapted to Faraday-type balance. DSC analysis was performed using Q2000 TA Instruments apparatus. The flow of nitrogen was used for the protection of samples. The shear band morphology was examined by scanning electron microscope JSM$-7000 \mathrm{~F}$.

\section{Results and discussion}

The temperature stability of the alloy was characterized by DTA analysis as Fig. 1 shows. The crystallization starts at the temperature of $510^{\circ} \mathrm{C}$ and therefore the heating up to $430^{\circ} \mathrm{C}$ saves the amorphous structure of alloy.

The hammer impact on the amorphous ribbon causes the shear band creation visible like linear steps on the free surface as it can be seen in Fig. 2. Increase of stored deformation energy causes the increase of shear 


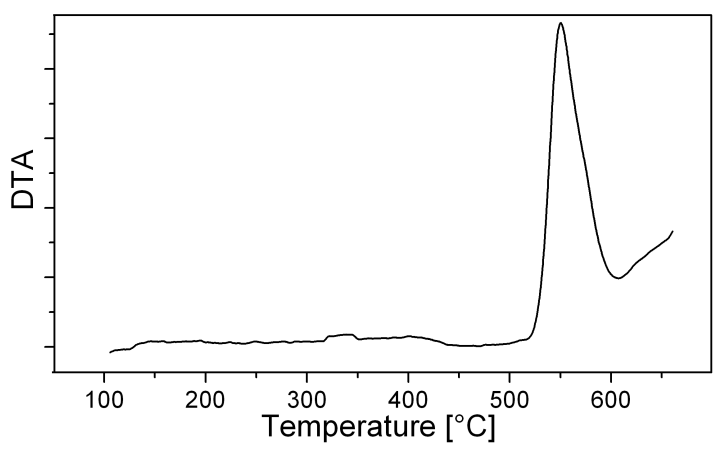

Fig. 1. DTA trace of $\mathrm{Fe}_{73.5} \mathrm{Nb}_{3} \mathrm{Cu}_{1} \mathrm{Si}_{13.5} \mathrm{~B}_{9}$ alloy.

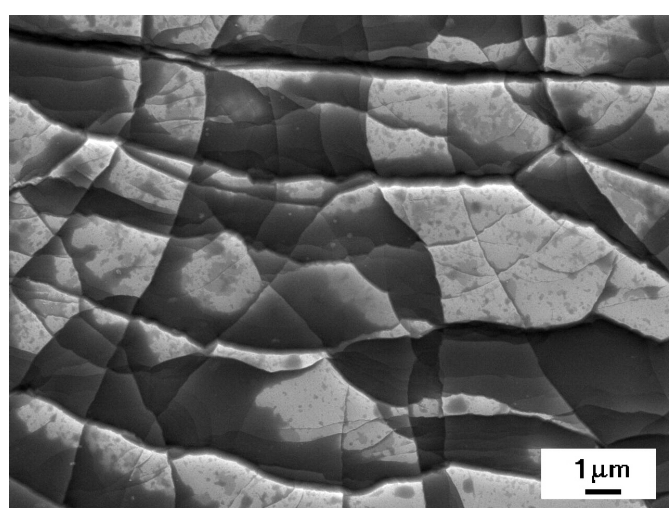

Fig. 2. The shear bands on the free surface of the deformed amorphous ribbon.

band density and more complicated distribution of the shear bands.

The thermomagnetic curves for the as quenched (undeformed) and deformed states measured under the linear heating with the rate of $20^{\circ} \mathrm{C} / \mathrm{min}$ can be seen in Fig. 3 . During heating up to the temperature of $430^{\circ} \mathrm{C}$, the transition to the paramagnetic state in the amorphous structure is observed. The Curie transition temperature in amorphous state (about $290^{\circ} \mathrm{C}$ ) is independent of the examined structural state. The different magnetic forces

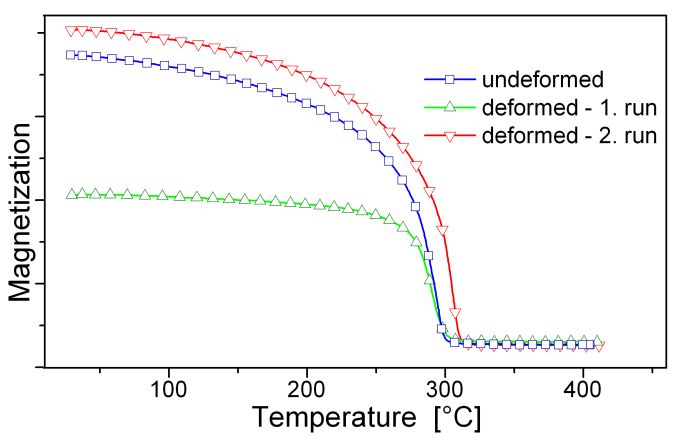

Fig. 3. The temperature dependences of the magnetization for the undeformed sample (first run) and for the deformed sample (two subsequent runs). for samples with different structure at temperatures below $T_{\mathrm{c}}$ can be caused by the structural differences in the shear bands and by the presence of the introduced stress field [10]. During the second run, the magnetization seems to be similar to that for the undeformed sample. So we can conclude that structural defects introduced by the deformation are annealed out during the first heating up to $430^{\circ} \mathrm{C}$.

DSC traces for two subsequent runs of as quenched and deformed samples are shown in Fig. 4. The Curie transition temperature values estimated from calorimetric measurements are summarized in Table. It is seen that the introduced deformation of the sample in as quenched state does not influence $T_{\mathrm{c}}$ value. On the contrary a shift of $T_{\mathrm{c}}$ to the higher temperatures after structural relaxation is observed for both, the deformed and the undeformed samples.

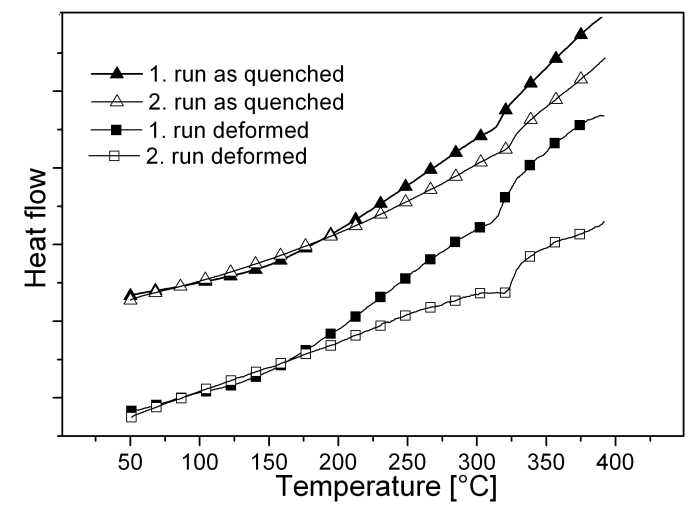

Fig. 4. The temperature dependences of the heat flow for deformed and undeformed samples during two subsequent heating runs.

TABLE

Curie transition temperatures determined from DSC measurements for as quenched and deformed samples.

\begin{tabular}{l|c|c}
\hline \hline \multirow{2}{*}{ Sample } & \multicolumn{2}{|c}{ Curie temperature } \\
& \multicolumn{2}{|c}{$\left[{ }^{\circ} \mathrm{C}\right]$} \\
\hline & 1. run & 2. run \\
\hline as quenched & 312.70 & 321.79 \\
deformed & 312.65 & 321.14
\end{tabular}

The difference in measured enthalpy changes between the first and the second heating run of amorphous alloy is proportional to the annihilated free volume. This difference is for the deformed sample significantly higher than for undeformed sample. During the plastic deformation, the free volume is introduced into the sample. The free volume localized into shear bands, causes local heating and enhances the plasticity of the amorphous alloy [8]. Decreasing of the free volume connected with structural relaxation leads to increase of $T_{\mathrm{c}}$, whereas the increase of free volume due to the deformation of the sample does 
not influence the Curie temperature, but the deformation causes the decrease in the measured magnetization. We can conclude that the areas outside shear bands are responsible for the decrease in the magnetization. The shear bands are very thin $[3,7]$, so the free volume increasing in the shear bands has only little effect on $T_{\mathrm{c}}$ shift. Higher portion of the sample volume outside shear band accumulates the elastic or the pseudoelastic energy and influences the measured magnetization.

\section{Conclusion}

We studied the influence of the plastic deformation via the shear band creation on the structural relaxation of Finemet alloy. The thermomagnetic study has shown that even small deformation led to a change in the magnetization of amorphous phase. During heating the structural relaxation occurs and the contribution of the modified structure inside shear bands vanishes and no differences in $T_{\mathrm{c}}$ were observed.

\section{Acknowledgments}

Authors are grateful to the Slovak Academy of Sciences - grant VEGA 2/0185/11 and Centre of Excellence Nanofluid for the support. This work was also supported by implementation of the project No. 26220120021 provided by the European Regional Development Fund.

\section{References}

[1] Y. Yoshizawa, S. Oguma, K. Yamauchi, J. Appl. Phys. 64, 6044 (1988).

[2] V. Ocelík, K. Csach, A. Kasardová, J. Miškuf, P. Švec, K. Krištiaková, I. Mat’ko, Scr. Mater. 35, 1301 (1996).

[3] J.J. Lewandowski, A.L. Greer, Nature Mater. 5, 15 (2006).

[4] E. Tabachnikova, V. Bengus, J. Miskuf, K. Csach, V. Ocelik, W. Johnson, V. Molokanov, Mater. Sci. Forum 343-346, 197 (2000).

[5] W.H. Jiang, F.E. Pinkerton, M. Atzmon, Acta Mater. 53, 3469 (2005).

[6] A. Inoue, A. Takeuchi, Acta Mater. 59, 2243 (2011).

[7] Z.H. Han, X.P. Li, L. He, W. Chen, F. Jiang, J. Sun, Intermetallics 19, 942 (2011).

[8] M. Kohda, O. Haruyama, T. Ohkubo, T. Egami, Phys. Rev. B 81, 092203 (2010).

[9] K. Csach, J. Miškuf, A. Juríková, J. Phys. Conf. Series 200, 082002 (2010).

[10] K. Csach, V. Ocelík, J. Miškuf, V.Z. Bengus, P. Duhaj, IEEE Trans. Magn. 30, 496 (1994). 